\title{
A PRODUÇÃO TEXTUAL NA ESCOLA E SEU ENSINO NOS MATERIAIS DIDÁTICOS UTIUIZADOS NO ESTADO DE SÃO PAULO
}

Tatiane Portela Vinhal**

Renata Junqueira de Souza***

Resumo: Este estudo pretende refletir sobre o ensino da escrita a partir da análise de propostas de produção textual presentes nos materiais didáticos utilizados no estado de São Paulo, no ano de 2011, nas 4ạ e 5a séries, atualmente 5ㅇ e 6ㅇa anos, tendo com critério: as expectativas em relação ao ensino da escrita dispostas nos Parâmetros Curriculares Nacionais de Língua Portuguesa. A concepção teórica adotada neste trabalho de abordagem-qualitativa é a do sociointeracinismo Ao final, pôde-se concluir que a propostas de produção textual dos materiais didáticos em questão, mesmo estando presentes alguns critérios das expectativas de escrita dos PCNLP, não promovem a função social do texto, aquele que o aluno usará no seu dia a dia.

Palavras-chave: Palavra 1. Parâmetros Curriculares Nacionais de Língua Portuguesa. 2. Manual didático 3. Sociointeracionismo. 4. Produção textual.

Introdução

Aprender para a vida é uma das preocupações necessárias para o ensino da língua materna, principalmente no que tange à escrita. Por essa razão, estudar e analisar como se dá o ensino da escrita é o que motivou este estudo, para tanto, utilizamos os manuais didáticos fornecidos pelo governo estadual de São Paulo da 4a e 5a séries, atualmente 5o e 6o anos, já que os estudantes, nesse período, passam por um momento de transição política, pedagógica e também pessoal e o livro didático se faz presente na relação professor-aluno e no processo de ensino-aprendizagem (WITZEL, 2002).

Essa passagem é política, porque primeiro os educandos estudam em instituições municipais. Conforme a Lei $n^{\circ}$ 9.034/96 de Diretrizes e Bases, o Município se responsabiliza pela educação infantil e ensino fundamental, enquanto o Estado se encarrega do ensino fundamental e médio. No que se referem às mudanças pedagógicas, os estudantes possuem uma professora responsável pela classe e por todas as disciplinas, recebem um tratamento

\footnotetext{
** Mestre, Unesp - Campus Presidente Prudente (SP), tativinhal@gmail.com.

*** Doutorado, Unesp- Campus Presidente Prudente (SP), recellij@gmail.com.
} 
mais infantilizado, a sala é decorada, os textos que são lidos remetem ao universo da criança, assim como as produções textuais que são solicitadas, geralmente fábulas. Enquanto na escola estadual, os alunos estão inseridos em outra dinâmica de ensino, com maior quantidade de disciplinas, consequentemente, aumento de professores com que têm contato. O espaço escolar também é distinto do que conheciam, é mais amplo, as salas possuem maior número de estudantes e as relações com os docentes exigem mais maturidade, já que os discentes passam a ser tratados como adolescentes e se comportam como tal, isso implica em rebeldia, questionamentos e desafio à autoridade do docente. Destacamos que esses apontamentos foram constatados mediante trabalho de campo realizado em setembro/2011 a novembro/2011 em duas escolas públicas de Presidente Prudente/SP, sendo uma municipal e outra estadual.

Nesse período de observação, procuramos verificar de que forma o ensino da escrita ressoa no cotidiano desses estudantes pertencentes à classe trabalhadora ${ }^{* * *}$, pois esses futuramente servirão de mão de obra ao mercado de trabalho. Como sabemos, nele é exigido dos operários um domínio mínimo da norma culta. Conforme Possenti (2006, p. 33), “o objetivo da escola é ensinar o português padrão, ou, talvez mais exatamente, o de criar condições para que ele seja aprendido".

Com essa afirmativa, indagamos: qual a razão de tantas pessoas saírem da escola sem ter a segurança de produzir um texto que atenda seu intento comunicativo com êxito, bem como ao leitor a que se dirige?

$\mathrm{Na}$ tentativa de compreendermos esse fenômeno, adotamos como objeto de investigação os livros didáticos das 4a e $5 \underline{a}$ séries ( 5 ㅇ e 60 anos) do ensino fundamental, fornecidos pelo Ministério da Educação (MEC) mediante Programa Nacional do Livro Didático (PNLD). Todavia, ao realizarmos a pesquisa de campo constatamos que esses não são trabalhados em sala, pois no 2ำ ciclo, o município de Presidente Prudente adere ao programa Ler e Escrever, que tem entre outros objetivos a formação docente e a elaboração um material didático que recebe o mesmo nome. Esse programa é desenvolvido pela Fundação para o Desenvolvimento para a Educação do Governo do Estado de São Paulo (FDE) com o apoio da Secretaria da Educação do Estado de São Paulo (SEE/SP). Já no 3 ciclo, os professores têm que cumprir o Currículo proposto pelo Estado. Esse documento dispõe que "o Currículo se completa com um conjunto de documentos dirigidos especialmente aos professores e aos alunos: os Cadernos do Professor e do Aluno, organizados por disciplina/série (ano)/bimestre" (SÃO PAULO, 2010, p. 08, grifo do autor).

**** Consideramos classe trabalhadora, as pessoas que além de viver do seu trabalho, são pouco remuneradas e vivem nas periferias (áreas distantes do centro da cidade). 
Para analisar esses manuais, tendo como recorte as propostas de produção textual, adotamos como perspectiva teórica: o sociointeracionismo.

A adoção desse pressuposto teórico funda-se na sua presença nos Parâmetros Curriculares Nacionais de Língua Portuguesa (PCNLP). Ao se pensar o ensino da língua materna sob a perspectiva sociointeracionista, o texto é considerado "um evento comunicativo em que convergem ações lingüísticas, sociais e cognitivas" (BEAUGRANDE, 1997, p. 10 apud MARCUSCHI, 2008, p. 72).

Assim, é pela linguagem que os interlocutores se comunicam e mais que isso, estabelecem relações entre si. Mediante a língua os sujeitos, falantes/ouvintes ou escritores/leitores, interagem e essa interação não ocorre ao acaso. Ela se orienta pelas ações e intenções que os sujeitos têm. Dessa forma, ela é maleável já que se adéqua às circunstâncias em que acontece (MARCUSCHI, 2008).

Essa concepção interacional (dialógica) da linguagem está presente nos Parâmetros Curriculares Nacionais de Língua Portuguesa (PCNLP). Segundo eles, espera-se que os educandos, ao completarem o ensino fundamental, sejam capazes de ler e escrever textos que circulam socialmente. Portanto, interagir pela linguagem, assumir a palavra - discursivamente - "significa que as escolhas feitas ao produzir um discurso não são aleatórias - ainda que possam ser inconscientes -, mas decorrentes das condições em que o discurso é realizado" (BRASIL, 1998, p. 21).

Dessa maneira, o texto e a sua produção emergem discussões a respeito de seu ensino. Marcuschi (2008) o compara a um tecido, em que estão entrelaçados sua entidade comunicativa e o seu aspecto histórico. $\mathrm{O}$ autor assevera que "de certo modo, pode-se afirmar que o texto é uma (re)construção do mundo e não uma simples refração ou reflexo" (MARCUSCHI, 2008, p. 72). Tal asserção explica a sua presença no ensino da língua, de acordo com o estudioso, isso é unânime entre linguistas teóricos e aplicados, além de orientar uma prática frequente na escola e nos PCNLP. No entanto, Marcuschi $(2008$, p. 51) inquieta-nos ao declarar que "a questão não reside no consenso ou na aceitação deste postulado, mas no modo como isto é posto em prática, já que muitas são as formas de trabalhar o texto".

É a partir da indagação de "como acontece a prática" no ensino da escrita que apresentamos, a seguir, o objetivo geral deste trabalho:

- Analisar as propostas de produção de textos escritos inseridas nos manuais didáticos distribuídos pelo Governo do Estado de São Paulo das 4as. e 5as. séries do ensino fundamental e as práticas adotadas em sala de aula usando como critério os objetivos de 
ensino para a produção textual escrita, propostos pelos Parâmetros Curriculares Nacionais de Língua Portuguesa.

Metodologia

Esta pesquisa de abordagem qualitativa caracteriza-se por ser um estudo de caso, em que as metodologias utilizadas foram, além da pesquisa biográfica, a análise documental.

A abordagem qualitativa enquadra-se no estudo de caso, pois "queremos estudar algo singular, que tenha um valor em si mesmo" (LÜDKE; ANDRÉ, 1986, p. 17).

Conforme Lüdke e André (1986), o estudo de caso visa à descoberta. No entanto, isso não significa que o investigador não possua pressupostos teóricos, mas ele deve, consoante as autoras (1986, p. 18), "se manter constantemente atento a novos elementos que podem emergir como importantes durante o estudo". Sendo assim, estar aberto às mudanças que o ambiente da pesquisa apresenta ao projeto faz parte da investigação.

A análise documental neste trabalho é essencial, sendo que os documentos investigados configuram-se também como objetos de estudos. Assim, eles são representados pelos materiais didáticos utilizados pelos alunos em sala de aula: as apostilas Ler e escrever: coletânea de atividades- 5o ano (4ạ série) (SÃO PAULO, 2010b) e os quatro volumes do Caderno do aluno de Língua Portuguesa - 5a série/6o ano (SÃO PAULO, 2009a; 2009b; 2009c; 2009d), todos eles distribuídos pelo Governo do Estado de São Paulo.

De acordo com Lüdke e André (1986), os documentos se destacam por ser uma fonte estável e rica. Esses adjetivos o tornam quase que atemporais, permitindo que sejam consultados, servindo de base a outros estudos. Além disso, deles podem ser "retiradas evidências que fundamentem afirmações e declarações do pesquisador" (LÜDKE, ANDRÉ, 1986, p. 39).

Para a análise das propostas de produção textual foram criadas categorias a partir das expectativas em relação à escrita presentes nos PCNLP (1998) para os 20 e 3ำ ciclos. Para isso, foi feita uma uniformização dessas expectativas em relação à escrita uma vez que há a ideia de continuidade tanto nos conteúdos, quanto nas habilidades que os estudantes da 4 a série/ 5o ano e da 5a série/6 ano devem adquirir.

Esses aspectos servirão como aporte para análise dos materiais em estudo neste trabalho. Após a categorização, foi realizada uma quantificação da presença de tais critérios nas atividades de produção de texto. A fim de elucidarmos esse levantamento, elaboramos 
tabelas em que se destacam as porcentagens que representam a presença de cada critério. Assim, os números encontrados a partir dessa metodologia dialogam com o intento principal deste texto, uma vez que é por meio dela que o alcançamos.

Pressupostos teóricos

A presença das políticas públicas teve seu pontapé inicial em 1996, com a Lei 9.394/96, mais conhecida como a Lei de Diretrizes Bases (LDB), que orienta a educação no país. Nesse contexto, o ensino de Língua Portuguesa, como todas as demais disciplinas, viu-se envolto a transformações referentes a perspectivas teóricas, conteúdos, práticas e implicações de cunho político. Essas últimas referem-se às orientações nacionais, estaduais, municipais para a educação e abarcam aspectos, como: a formação de professores, distribuição de materiais didáticos, entre outros.

Além desses fatores educacionais e políticos, existem os externos. Uma vez que a realidade social ganhou uma nova configuração provocada pela industrialização e consequentemente pela urbanização, mediante a expansão dos meios de comunicação e das novas tecnologias que consolidaram a utilização da escrita (BRASIL, 1998). Diante desse cenário, a escrita estabelece-se como uma tecnologia. Segundo Marcuschi (2001), ela é mais do que isso, pois é por meio da escrita que se manifestam os diversos tipos de letramento. Dessa forma, ela "se tornou um bem social indispensável para enfrentar o dia-a-dia, seja nos centros urbanos ou na zona rural" (MARCUSCHI, 2001, p. 16, grifo do autor), já que se impôs nas sociedades modernas, constituindo-se também um bem cultural.

A instituição responsável pelo ensino da escrita é a escola, e nesse ambiente, documentos oficiais orientam o trabalho docente, que recai sobre a aprendizagem dos alunos. Assim, no contexto em estudo, estão presentes os Parâmetros Curriculares Nacionais de Língua Portuguesa para o Ensino Fundamental (1997; 1998), do Currículo do Estado de São Paulo: Linguagens, códigos e suas tecnologias (2010a) e dos Subsídios para a Educação Infantil e Ensino Fundamental (2003), elaborado pela Secretaria Municipal de Presidente Prudente/SP. Vale ressaltar que a concepção teórica do sociointeracionismo está presente em todos eles, o que nos permite afirmar a presença do diálogo entre essas orientações. Por essa razão, um breve apanhado desses documentos se faz pertinente.

Os propósitos que circundam a disciplina Língua Portuguesa, consoante os PCNLP, é o de desenvolver nos cidadãos a "sua capacidade de compreender textos orais e escritos. De assumir a palavra e produzir textos, em situações de participação social" (BRASIL, 1997, p. 37). 
Para que isso se realize, a aprendizagem deve estar incluída em situações concretas de intervenção (BRASIL, 1997). A partir dessas premissas constrói-se a meta do ensino de leitura, que de acordo com os PCNLP, é a de "formar leitores que sejam também capazes de produzir textos coerentes, coesos, adequados e ortograficamente escritos" (BRASIL, 1997, p. 40), enquanto a finalidade do trabalho com a produção de textos é a de: "formar escritores competentes capazes de produzir textos coerentes, coesos e eficazes" (BRASIL, 1997, p. 47).

Conforme essas afirmações, constamos que leitura e escrita estão imbricadas no ensino e na aprendizagem da língua e ambas devem ser vistas pela escola como práticas sociais. Portanto, os PCNLP caracterizam um produtor de textos aquele que planeja o seu discurso em função do seu objetivo e do leitor a quem se destina (BRASIL, 1997) e para aprender a escrever:

É preciso que se coloquem as questões centrais da produção desde o início: como escrever, considerando, ao mesmo tempo, o que pretendem dizer e a quem o texto se destina - afinal, a eficácia da escrita se caracteriza pela aproximação máxima entre a intenção do dizer, o que efetivamente se escreve e a interpretação de quem lê. É preciso que aprendam os aspectos notacionais da escrita (o princípio alfabético e as restrições ortográficas) no interior de um processo de aprendizagem dos usos da linguagem escrita. É disso que se está falando quando se diz que é preciso "aprender a escrever, escrevendo" (BRASIL, 1997, p.48).

De acordo com os PCNLP (1997), um aspecto que se impõe na aprendizagem da escrita é a importância da diversidade dos gêneros textuais. São eles que permitem que os sujeitos testemunhem a utilização dessa habilidade nas múltiplas circunstâncias comunicativas e possibilita o "defrontar-se com as reais questões que a escrita coloca a quem se propõe produzi-la, arriscar-se a fazer como consegue e receber ajuda de quem já sabe escrever" (BRASIL, 1997, p. 48).

Além de favorecer o contato dos alunos com a multiplicidade de gêneros, as diretrizes nacionais elencam entre as ações ligadas à escrita a revisão. Esse importante item no processo da escrita integra a produção textual tanto como prática discursiva e social, quanto uma atividade em que se aprende a língua refletindo-a a partir de seus usos. $\mathrm{O}$ ato de rever e posteriormente reescrever forçam seu locutor a planejar o seu texto pensando em suas condições de uso, adequando-o ao seu destinatário, por isso é uma atividade social e dialógica. Já como exercício metalinguístico, o sujeito aprende sobre a língua, bem como suas regras e coloca esse conhecimento em ação, tendo como objetivo a comunicação.

Um aspecto notado durante a leitura dos PCNLP para os quatro ciclos do ensino fundamental é que há uma delimitação bem clara entre os conteúdos a serem tratados nos cinco primeiros anos escolares do ensino fundamental. Ou seja, o documento esclarece que no 
primeiro ciclo a preocupação é quanto à alfabetização dos discentes, o segundo é voltado para a leitura como compreensão. Há uma seção para o ensino e aprendizagem de Língua Portuguesa para o primeiro ciclo (BRASIL, 1997, p. 101) e outra para o 2o ciclo (BRASIL, 1997, p. 123). Nos dois últimos ciclos devem ser aprofundadas questões relativas aos aspectos linguísticos, mas não há uma distinção entre o que ensinar e aprender no 3o ou 40 ciclo.

Deduzimos em relação a essa organização do documento que nos dois últimos ciclos há uma continuidade, talvez maior, no ensino e aprendizagem. No entanto, pairam dúvidas quanto à clareza do que seria ideal e das expectativas de aprendizagem para cada um desses períodos. Contudo, há outro fator que pode confundir o docente no que tange aos objetivos de ensino em relação ao processo de produção de textos escritos para o 20 ciclo, pois eles são colocados juntos com os aspectos referentes à leitura. Como veremos:

As práticas de educativas devem ser organizadas de maneira a garantir, progressivamente, que os alunos sejam capazes de:

- Compreender o sentido das mensagens orais e escritas de que é destinatário direto ou indireto, desenvolvendo sensibilidade para reconhecer a intencionalidade implícita e conteúdos discriminatórios ou persuasivos, especialmente nas mensagens veiculadas pelos meios de comunicação;

- Ler automamente diferentes textos dos gêneros previstos pra o ciclo, sabendo identificar aqueles que respondem às suas necessidades imediatas e selecionar estratégias adequadas para abordá-los;

- Utilizar a linguagem para expressar sentimentos, experiências e idéias, acolhendo, interpretando e considerando os das outras pessoas e respeitando os diferentes modos de falar;

- Utilizar a linguagem oral com eficácia, começando a adequá-la a intenções e situações comunicativas que requeiram o domínio de registros formais, o planejamento próprio do discurso, a coerência na defesa dos pontos de vista e na apresentação de argumentos e o uso de procedimentos de negociação de acordos necessários ou possíveis;

- Produzir textos escritos, coesos e coerentes, dentro dos gêneros previstos para o ciclo, ajustados a objetivos e leitores determinados;

- Escrever textos com domínio da separação em palavras, estabilidade de palavras de ortografia regular e de irregularidades mais frequentes na escrita e utilização de recursos do sistema de pontuação para dividir o texto em frases;

- $\quad$ Revisar seus próprios textos a partir de uma primeira versão e, com a ajuda do professor, redigir as versões necessárias até considerá-lo suficientemente bem escrito para o momento (BRASIL, 1997, p. 79-80).

Nos 30 e 40 ciclos as expectativas em relação às aprendizagens de escrita estão definidas separadamente, como mostra a citação:

No processo de produção de textos escritos, espera-se que o aluno: 
- redija diferentes tipos de textos, estruturando-os de maneira a garantir:

*a relevância das partes e dos tópicos em relação ao tema e propósitos do texto;

* a continuidade temática;

* a explicitação de informações contextuais ou de premissas indispensáveis à interpretação;

- realize escolhas de elementos lexicais, sintáticos, figurativos e ilustrativos, ajustando-as às circunstâncias, formalidade e propósitos da interação;

- $\quad$ utilize com propriedade e desenvoltura os padrões da escrita em função das exigências do gênero e das condições de produção;

- $\quad$ analise e revise o próprio texto em função dos objetivos estabelecidos, da intenção comunicativa e do leitor a que se destina, redigindo tantas quantas forem as versões necessárias para considerar o texto produzido bem escrito (BRASIL, 1998, p. 51).

Esses também serão os aspectos que serão analisados nas propostas de produção textual nos materiais didáticos selecionados para este artigo.

O Currículo do Estado de São Paulo foi proposto em 2008 pela Secretaria Estadual de Educação de São Paulo (SEE/SP) e sua finalidade é a de apoiar os trabalhos realizados nas instituições públicas de ensino e melhorar a qualidade da aprendizagem dos estudantes (SÃO PAULO, 2010). Esse documento "apresenta os princípios orientadores do currículo para uma escola capaz de promover as competências indispensáveis ao enfretamento dos desafios sociais, culturais e profissionais do mundo contemporâneo" (SÃO PAULO, 2010, p. 07).

Dessa forma, enfatiza-se a leitura e a escrita, que não são tratadas como conteúdos específicos de uma única disciplina, mas devem estar articuladas a todas as outras matérias da grade curricular. Logo, é necessário que os esforços se voltem para as expectativas do que os alunos precisam aprender durante o período escolar. Nesse contexto, as habilidades desenvolvidas pela escola, conforme o Currículo, aproximam-se mais do aprender para a vida do que com o aprender para a instituição escolar. Assim, exploram-se, nesse documento, as situações de aprendizagem. Por essa razão, as competências "caracterizam modos de ser, de raciocinar e de interagir que podem ser depreendidos das ações e de tomadas de decisão em contextos de problemas, de tarefas ou de atividades" (SÃO PAULO, 2010, p. 12) e se baseiam na seguinte tríade: adolescente, professor e o conteúdo das disciplinas (SÃO PAULO, 2010).

Ao centrar-se na aprendizagem, o Currículo adota a postura de focar suas ações nos estudantes. Essa mesma atitude é encontrada nos PCN e segue uma tendência apontada pela Lei de Diretrizes e Base da Educação (Lei no 9.394/1996). Essa lei promulga que mais do que liberdade ao ensino, a escola deve defender o direito de aprender. 
O material didático elaborado pelo Estado está previsto no documento. Segundo ele,

O Currículo se completa com um conjunto de documentos dirigidos especialmente aos professores e alunos: os Cadernos do Professor e do Aluno, organizados por disciplina/série (ano)/bimestre. Neles, são apresentadas Situações de Aprendizagem para orientar o trabalho do professor no ensino dos conteúdos disciplinares específicos e a aprendizagem dos alunos (CURRíCULO, 2010, p. 08, grifo do autor).

Já objetivo do documento municipal é o de "subsidiar a prática pedagógica dos professores da rede municipal, principalmente em relação ao plano de ensino" (PRESIDENTE PRUDENTE, 2003, p. 5). Ele vem a atender a uma demanda dos profissionais da educação que é a "de se construir um referencial curricular do município" (PRESIDENTE PRUDENTE, 2003, p. 5). Seus pressupostos teóricos condizem com os dos PCN, em que temos a perspectiva interacional dialógica da linguagem, bem como os teóricos do sociointeracionismo, como Vygostsky.

No que se refere ao ensino de Língua Portuguesa para a 3a e 4a séries (4으 e 5o anos), o texto municipal dispõe dos mesmos objetivos e conteúdos que são apresentados pelos PCNLP para o segundo ciclo, o mesmo ocorre na descrição dos conteúdos gerais, nos gêneros textuais adequados para o trabalho com a linguagem oral e escrita e também com o que se relaciona à prática de produção de texto, à análise e reflexão sobre a língua. Não se encontram rupturas teóricas, lexicais ou mesmo semânticas com os PCNLP, o que se percebe são pequenas adaptações de um texto em relação ao outro.

De acordo com as diretrizes nacionais, estaduais e municipais, o texto é um aspecto central no ensino da Língua Portuguesa e também das outras disciplinas. Ele se apresenta como palavra-chave nesta pesquisa por fazer parte da expressão "produção de texto" e figura como suporte, pois é por meio dele que a linguagem é veiculada. Para nos ajudar nessa noção, buscamos sua compreensão em alguns autores, como Costa Val $(1999,2004)$, Koch (2001) e Marcuschi (2008). O entendimento que esses possuem a respeito desse conceito é convergente, como veremos.

A diversidade dos gêneros textuais é outro elemento crucial no ensino e na aprendizagem da escrita e faz-se necessária no ensino de Língua Portuguesa, pois colabora com as suas experiências que resultarão na dialogia da linguagem e, consequentemente, na interação. Conforme Curado (2010, p. 148, grifo do autor):

Admitir a natureza social da linguagem e o caráter interacional e dialógico da língua impõe-nos a necessidade de promover o contato do aluno com 
diferentes gêneros discursivos (orais e escritos) de diferentes ordens, em organização curricular progressiva, no processo de leitura (e de escrita), inclusive, com variações de construção composicional de um mesmo gênero.

Sendo assim, os gêneros textuais constituem-se um importante item da aprendizagem quando se pretende formar produtores de textos. E essa será uma das categorias a ser analisadas nos materiais.

Para entender as concepções e práticas que permeiam o ensino da escrita é necessária a discussão a respeito das atividades que envolvem esse ato, ou seja: a composição, a redação e a produção textual.

Conforme Guedes (2009, p. 88), "composição, redação e produção textual são expressões sinônimas, isto é, designam o mesmo fenômeno, a saber, a ação de escrever textos". Porém, elas carregam em seu significado a maneira que se concebe o ensino da escrita e o modo de se relacionar com a linguagem.

Para o autor, o termo "composição" é o mais antigo e está aliado à concepção que fortalece a gramática tradicional, tomando a linguagem como expressão do pensamento. Por essa razão, ele pertence a "uma visão elitista e estática, dominante num Brasil dirigido por bacharéis das leis" (GUEDES, 2009, p. 88). Nesse contexto, Guedes (2009, p. 88) afirma que escrever não se relaciona com criação, mas se configura num modo "peculiar de arranjar esse material que a tradição juntou".

Com o passar do tempo, a valorização da composição entra em declínio, mas não em desuso nas escolas. A partir dos anos 1950, no período desenvolvimentista do país, a expressão "redação" emerge nas salas de aula. O emprego desse vocábulo expressa a ideia de que a linguagem é comunicação, a língua é "um código pelo qual o emissor cifra sua comunicação por meio do qual é transmitida" (GUEDES, 2009, p. 89) .

O ensino que promove a escrita por meio de composições ou redações se assemelha, pois ambas as expressões vinculam-se a sugestões aleatórias, em temas desarticulados (CITTELLI, 2001). O texto não tem outra função além de circular no ambiente escolar, não importa a sua mensagem, mas a maneira como ela é escrita, ou seja, essa atividade é objeto de correção no que tange aos aspectos normativos da língua, extinguindo a possibilidade de relação do texto feito na e para escola e a sua prática social.

Por último, Geraldi (2006) nos apresenta a concepção em que a "linguagem é uma forma de interação" (GERALDI, 2006, p. 41, grifo do autor). Sob essa perspectiva a linguagem extrapola a função de transmitir informação e passa a ser lugar de interação (GERALDI, 2006). Assim, a produção de texto é uma forma de interação verbal experienciada no ambiente 
escolar e resulta num momento dialógico de aprendizagem, em que o texto escrito pelo estudante é produto de seu contexto, de sua intenção (mesmo que dados pelo manual didático). A produção textual é um pequeno exemplo das diversas maneiras de se usar a linguagem, a palavra e seus saberes da língua para interagir com o outro. Do ponto de vista do locutor, fazer uso da língua, trata-se de:

utilizar as formas normativas (admitimos, por enquanto, a legitimidade destas) num dado contexto concreto. Para ele, o centro de gravidade da língua não reside na conformidade à norma da forma utilizada, mas na nova significação que essa forma adquire no contexto (BAKHTIN, 2010, p. 95).

A concepção sociointeracionista está presente nos PCNLP e verificaremos se está presente nas propostas de produção textual dos manuais didáticos de 4a e 5a séries (5으 e 6으 anos) fornecidos pelo Governo do Estado de São Paulo.

\section{Análise de dados}

Para a analisarmos as proposta de produção textual encontradas nos manuais distribuídos pelo Governo do Estado de São Paulo definimos seis categorias que abrangem as expectativas de ensino para a escrita de que tratam os $\operatorname{PCNLP}(1997 ; 1998)$ para o 2 을 e 3 은 ciclos do ensino fundamental.

No 2 - ciclo, temos:

As práticas educativas devem ser organizadas de maneira a garantir, progressivamente, que os alunos sejam capazes de:

(...)

- Produzir textos escritos, coesos e coerentes, dentro dos gêneros previstos para o ciclo, ajustados a objetivos e leitores determinados;

- $\quad$ Escrever textos com domínio da separação em palavras, estabilidade de palavras de ortografia regular e de irregularidades mais frequentes na escrita e utilização de recursos do sistema de pontuação para dividir o texto em frases;

- $\quad$ Revisar seus próprios textos a partir de uma primeira versão e, com a ajuda do professor, redigir as versões necessárias até considerá-lo suficientemente bem escrito para o momento (BRASIL, 1997, p. 79-80).

Para o 3ํㅗ ciclo as expectativas em relação às aprendizagens de escrita são:

No processo de produção de textos escritos, espera-se que o aluno: 
- redija diferentes tipos de textos, estruturando-os de maneira a garantir:

*a relevância das partes e dos tópicos em relação ao tema e propósitos do texto;

* a continuidade temática;

* a explicitação de informações contextuais ou de premissas indispensáveis à interpretação;

- realize escolhas de elementos lexicais, sintáticos, figurativos e ilustrativos, ajustando-as às circunstâncias, formalidade e propósitos da interação;

- $\quad$ utilize com propriedade e desenvoltura os padrões da escrita em função das exigências do gênero e das condições de produção;

- $\quad$ analise e revise o próprio texto em função dos objetivos estabelecidos, da intenção comunicativa e do leitor a que se destina, redigindo tantas quantas forem as versões necessárias para considerar o texto produzido bem escrito (BRASIL, 1998, p. 51).

Uma dificuldade que se impõe é a da uniformização dessas expectativas em relação à aprendizagem da escrita, pois apesar de serem diferentes, consideramos que elas são complementares, uma vez que há a ideia de continuidade tanto nos conteúdos, quanto nas habilidades que os estudantes da 4a série/ 5o ano e da 5a série/6으 ano devem adquirir. Por essa razão, julgamos que para obter melhores resultados deveríamos partir de aspectos que são comuns, a saber:

a) a diversidade de gêneros textuais que é solicitada nas propostas;

b) aspectos normativos da língua, em que estão incluídos a ortografia, a sintaxe e o léxico, ou seja, se as atividades mencionam que o produtor de texto se atente a esses elementos;

c) aspectos referentes à estrutura do texto, isto é, se nas propostas há menção de algumas características do gênero ou da tipologia textual e o seu objetivo;

d) a reescrita e revisão, já que em ambos os ciclos esses itens são mencionados como uma característica do produtor de texto competente ;

e) "o texto como pretexto", anunciamos esse critério, visto que, o texto é tido como elemento central no ensino de Língua Portuguesa e queremos verificar se as propostas de produção textual vêm acompanhadas de textos que sirvam para contextualizar a produção ou que, simplesmente, sirvam de exemplo para o texto escrito pelo discente;

f) se a proposta de produção textual indica um contexto ou pressupõe um leitor.

Antes de mostrar os dados levantados, é necessário conhecer um pouco dos manuais analisados.

A coletânea de atividades do Ler e Escrever (SÃO PAULO, 2010b) da 4a série/5o ano é divida da seguinte maneira: Atividades do projeto didático "Uma lenda, duas lendas, tantas 
lendas"; Atividades do projeto didático "Universo ao meu redor"; Coletânea de textos da sequência didática "Caminhos do verde"; Coletânea de textos da sequência didática "Lendo notícias para ler o mundo"; Atividades da sequência didática "Estudo de pontuação"; Atividades da sequência didática "Estudo da ortografia"; "Atividades de Matemática". Desse material analisamos as atividades dos projetos, das sequências didáticas e as coletâneas de textos, deixando de fora as "Atividades de Matemática".

$\mathrm{Na}$ apresentação do Guia há um aviso aos professores de que não existem propostas de produção de texto nesse manual. No entanto, após uma leitura cuidadosa, consideramos que essas atividades são sugeridas no material, uma vez que compreendemos a produção de texto, como o ato de escrever atendendo a uma intenção e isso implica diversos tipos e gêneros textuais. Segundo Jolibert et al (1994, p. 191-192), "escrever é produzir mensagens reais, com intencionalidade e destinatários reais. (...) Escrever é produzir textos ou, melhor, tipos de textos, em função das próprias necessidades e projetos: cartas, cartazes, receitas, notícias, histórias, poemas, etc".

Verificamos em todo o Ler e escrever: coletânea de atividades (SÃO PAULO, 2010b) um total de 13 atividades de produção de texto. Sendo que essas não se limitam só à disciplina de Língua Portuguesa, já que esse material é único para todos os conteúdos escolares e a delimitação é bastante clara no que se refere aos conhecimentos matemáticos. As propostas foram analisadas tendo em vista as categorias elencadas no início deste capítulo e os dados encontrados foram dispostos em forma de tabela e em uma proposta verificamos mais de uma categoria, por isso o valor total de $100 \%$ não pôde ser aplicado.

\section{QUADRO 01:}

\begin{tabular}{|l|c|}
\multicolumn{2}{|c|}{$\begin{array}{c}\text { Categorias encontradas nas propostas de produção textual } \\
\text { na coletânea de atividades do Ler e escrever } \\
\text { 4a série/50 ano }\end{array}$} \\
\hline Texto como pretexto & $76,92 \%$ \\
\hline Diversidade de gêneros textuais & $46,15 \%$ \\
\hline Estrutura do texto & $23,07 \%$ \\
\hline Reescrita e revisão & $23,07 \%$ \\
\hline Contexto e leitor & $23,07 \%$ \\
\hline Aspectos normativos da língua & $7,69 \%$ \\
\hline
\end{tabular}

Organização: VINHAL (2012) 
Constatamos que "o texto como pretexto" é a categoria que sobressai entre as demais que elencamos, e a que menos é contemplada é a dos "aspectos normativos da língua". Quanto à diversidade de gêneros, as propostas de produção textual estimulam: a confecção de resumos (4); descrições a partir de imagem (1); reescrita de uma narrativa (1); lista de providências a serem tomadas para a realização de um passeio (1); roteiro de passeio (1); organização de um dossiê sobre o passeio (1); registro de conclusões do que foi aprendido sobre um tema (2); e o registro do papel da notícia (1); e a definição de um conceito (1). Dessa forma, a narrativa é a tipologia textual privilegiada nesse manual, estando ela presente também nos textos que servem como pretexto para a produção textual.

Já o material da 5a série (60 ano) é dividido em quatro volumes do Caderno do Aluno (SÃO PAULO, 2009a; 2009b; 2009c; 2009d) da 5a série/6 ano. Nele constatamos 32 propostas de produção de texto. Os resultados estão demonstrados no Quadro 02.

\section{QUADRO 02:}

\begin{tabular}{|c|c|}
\hline \multicolumn{2}{|c|}{$\begin{array}{l}\text { Categorias encontradas nas propostas de produção textual } \\
\qquad \text { no Caderno do Aluno } \\
5 \text { a série/60 ano }\end{array}$} \\
\hline Estrutura do texto & $43,75 \%$ \\
\hline Texto como pretexto & $37,5 \%$ \\
\hline Reescrita e revisão & $34,37 \%$ \\
\hline Contexto e leitor & $34,37 \%$ \\
\hline Diversidade de gêneros & $25 \%$ \\
\hline $\begin{array}{lll}\text { Aspectos } & \text { normativos } & d a \\
\text { língua } & & \end{array}$ & $21,87 \%$ \\
\hline
\end{tabular}

Organização: VINHAL, 2012.

Além de serem em maior quantidade, as propostas de produção escrita na 5 a série/6으 ano indicam números mais equilibrados nas categorias. As atividades de produção textual que sugerem uma atenção do estudante quanto à estrutura textual aparecem em primeiro lugar $(43,75 \%)$ e o aspecto menos frequente é o referente aos elementos normativos da língua. Destaca-se que assim como na 4a série/ 5a ano, o tipo textual "narrativa" é a base para todos os gêneros textuais trabalhados nessas apostilas. 
As propostas sugerem a produção dos seguintes gêneros: narrativas (22), sendo que dentro desse gênero incluímos: a continuação de histórias (12), recontar uma história (4), reescrever uma história (2); criar histórias em cima de casos (1), imagens (1) e enredos (3), narrativa de enigma (1); letra de música (3); resumo (2); regra para gincana (1); descrição (1); diálogo (1); crônica (2).

\title{
Considerações finais
}

As diferenças dos materiais da 4a e 5a série quanto à produção de texto são visíveis e isso refletirá na prática das docentes e na utilização dos manuais em sala de aula, destacamos a partir disso as seguintes incongruências: o Ler e escrever: coletânea de atividades (SÃO PAULO, 2010b) não enfoca um trabalho real de produção de texto. Vimos que essa atividade acontece de maneira precária, enquanto no material da 5a série, a produção de texto acontece de maneira mais efetiva e objetiva. Diante do que foi visto nesses materiais, afirmamos que no Ler e escrever: coletânea de atividades (SÃO PAULO, 2010b) há um trabalho mais com a reflexão sobre a estrutura dos gêneros narrativos do que de produção desses textos; o material da 4a série também apresenta uma maior variedade de gêneros dentro do tipo narrativo, tais como: lendas, resumos, notícias, roteiro de passeios, já o Caderno do aluno (2009a; 2009b; 2009c; 2009d) enfatiza gêneros narrativos, mas são: letras de música, contos e crônicas. Percebemos no estudo deste último manual uma maior proximidade com a perspectiva sociointeracionista, assim, ele tenta estimular a produção de textos, prevendo objetivos e leitores aos textos produzidos pelos alunos, bem como uma experiência no processo de produção da escrita, enfatizando a revisão e a reescrita, tais aspectos são escassos no Ler e escrever: coletânea de atividades (SÃO PAULO, 2010b).

\section{The textual prduction in school and its teaching in the didatic materials used in the state of São Paulo}

\begin{abstract}
This study intends to reflect on the teaching of writing based on the analysis of textual production proposals present in the teaching materials used in the State of São Paulo, in the year 2011, in the 4th and 5 th grades, currently 5 th and 6 th years, with the following criteria: The expectations regarding the teaching of writing arranged in the National Curriculum Parameters of Portuguese Language. The theoretical conception adopted in this work of qualitative-approach is the one of sociointeracinismo. In the end, it was possible to conclude that the proposals of textual production of the didactic materials in question, even if some criteria of the writing expectations of the PCNLPs are present, do not promote the social function Of the text, the one that the student will use in his daily life.
\end{abstract}

Key words: 1 . National Curriculum Parameters of Portuguese Language. 2. Teaching manual. 3. Text production. 4. Sociointeracionism 


\section{Referências}

BAKHTIN, Mikhail Mikhailovithch. Marxismo e filosofia da linguagem: problemas fundamentais do método sociológico da linguagem. Trad. Michel Lahud e Yara Frateschi Vieira, com a colaboração de Lúcia Teixeira Ewisnik e Carlos Henrique D. Chagas Cruz. 14 ed. São Paulo: Hucitec, 2010.

BRASIL. Secretaria de Educação Fundamental. Parâmetros curriculares nacionais: primeiro e segundo ciclos do ensino fundamental: língua portuguesa/Secretaria de Educação Fundamental. - Brasília: MEC/SEF, 1997.

BRASIL. Secretaria de Educação Fundamental. Parâmetros curriculares nacionais: terceiro e quarto ciclos do ensino fundamental: língua portuguesa/Secretaria de Educação Fundamental. - Brasília: MEC/SEF, 1998.

CITELLI, Beatriz. Produção e leitura de textos no ensino fundamental. 2. Ed. São Paulo: Cortez, 2001, v.7.

COSTA VAL, Maria da Graça. Avaliar redações: uma questão mais ampla do que parece. Dois pontos: Teoria e Prática em Educação. Belo Horizonte, v. 2, n.113, 1992, p. 59-61.

. Texto e textualidade. In: Redação e textualidade. São Paulo: Martins Fontes, 1999, p. 03-16.

. Texto, textualidade e textualização. Pedagogia Cidadã. Cadernos de Formação Língua Portuguesa, UNESP - São Paulo, 2004, v.1. p. 113-124.

CURADO, Odilon Helou Fleury. Linguagem dialógica: práticas de leitura e produção de texto. In: OSOSRIO, Ester Myriam Rojas (org.). Mikhail Bakhtin: Cultura e vida. São Carlos: Pedore \& João Editores, 2010, p. 141-152.

GERALDI, João Wanderley. Portos de passagem. São Paulo: Martins Fontes, 1993.

. Concepções de linguagem. In: GERALDI, João Wanderley; ALMEIDA, Milton José de; leite, Lígia Chiappini de Moraes; OSAKABE, Haquira; POSSENTI, Sírio; SILVA, Lilian Lopes Martin da; FONSECA, Maria Nilma Goes da; BRITTO, Luiz Percival Leme (Org.). 0 texto na sala de aula. 4a. Ed. São Paulo: Ática, 2006, p. 39- 45.

GUEDES, Paulo Coimbra. Olhar, imaginar, organizar, escrever. In: Da redação à produção textual: o ensino da escrita. São Paulo: Parábola Editorial, 2009. p. 87-122.

JOLIBERT, Josette. Formando crianças produtoras de textos. JOLIBERT, Josette (coord); trad. Walkiria M. F. Settineri e Bruno Charles Magne. Porto Alegre: Artes Médicas, 1994.

$\mathrm{KOCH}$, Ingedore Villaça. A construção textual do sentido. In: O texto e a construção dos sentidos. 5a Ed. São Paulo: Contexto, 2001. p. 9-58.

LÜDKE, Menga; ANDRÉ, Marli, E. D. A. Pesquisa em educação: abordagens qualitativas. São Paulo: EPU, 1986. 
MARCUSCHI, Luiz Antônio. Oralidade e letramento. In: Da fala para a escrita: atividades de retextualização. São Paulo: Cortez, 2001. p. 15-43.

Processos de produção textual. In: Produção textual, análise de gêneros e compreensão. São Paulo: Parábola Editoria, 2008. p. 49-144.

POSSENTI, Sírio. Sobre o ensino de português na escola. In: GERALDI, João Wanderley; ALMEIDA, Milton José de; leite, Lígia Chiappini de Moraes; OSAKABE, Haquira; POSSENTI, Sírio; SILVA, Lilian Lopes Martin da; FONSECA, Maria Nilma Goes da; BRITTO, Luiz Percival Leme (Org.). 0 texto na sala de aula. 4a. Ed. São Paulo: Ática, 2006, p. 32-38.

PRESIDENTE PRUDENTE (Município). Subsídios para a Educação Infantil (4 a 6 anos) e Ensino Fundamental (1a a 4a série). MENDES, Cíntia Cristina Teixeira (org.). Secretaria Municipal de Educação de Presidente Prudente. 2003.

SÃO PAULO (Estado). Currículo do Estado de São Paulo: linguagens, códigos e suas tecnologias. Secretaria de Educação. São Paulo: SEE, 2010a.

SÃO PAULO (Estado). Ler e escrever: coletânea de atividades - 5o ano (4a série). Secretaria de Educação, Fundação para o desenvolvimento da Educação; adaptação do material original, Marisa Garcia, Andréa Beatriz Frigo. 2 ed. São Paulo: FDE, 2010b.

SÃO PAULO (Estado) Secretaria da Educação. Ler e escrever: guia de planejamento e orientações didáticos; professor- 4a série. Secretaria da Educação, Fundação para o Desenvolvimento da Educação; adaptação do material original: Marisa Garcia; Andréa Beatriz Frigo. 2a Ed. São Paulo: FDE, 2010c.

SOUZA, Renata Junqueira; SOUSA, Ana Claudia de; CASTRO, Priscila Cristina Vieira de; SOUZA, Grazielle Campos de. Leitura do professor, leitura do aluno: processos de formação continuada. In: PINHO, Sheila Zambello de; SAGLIETTI, José Roberto Corrêa (Org.) UNESP/ Escolas Núcleos de Ensino. São Paulo: Editora UNESP, 2006, v. 1. p. 217-230.

WITZEL, Denise Gabriel. Identidade e livro didático: movimentos identitários do professor de língua portuguesa. 2002. Dissertação (Mestrado) - Universidade Estadual de Maringá convênio com a UNICENTRO, Programa de Pós-Graduação em Linguística Aplicada. 